\title{
The Social Intervention for Adolescence with Autism Spectrum Disorder (ASD): A Systematic Review
}

\author{
Faqihul Muqoddam \\ Faculty of Psychology \\ Universitas Airlangga, Indonesia \\ faqihul.muqoddam-2018@psikologi.unair.ac.id \\ Wiwin Hendriani \\ Faculty of Psychology \\ Universitas Airlangga, Indonesia \\ wiwin.hendriani@psikologi.unair.ac.id
}

\begin{abstract}
The systematic review aims to find the types of effective social interventions applied to adolescents with autism spectrum disorders (ASD) in several articles selected through the screening process in 2010-2018. The review was conducted with search keywords "social intervention" and "autism spectrum disorder" on 3 online databases, namely ERIC, Springer Link, and ScienceDirect. There were 8 articles reviewed from a total of 420 obtained from screening results according to inclusion and exclusion criteria. The results showed that the social skills of adolescents with autism spectrum disorder (ASD) can be improved and developed through several interventions such as the Program for the Education and Enrichment of Relational Skills (PEERS), Multimodal Anxiety and Social Skills Intervention (MASSI), Peer Network Intervention, and CBT-CSCA. The four interventions were significantly able to increase knowledge and social skills in adolescents who experienced ASD so that it could be a reference in the intervention process in subsequent applications. While measurement with the Social Skills Rating System (SSRS) by Gresham \& Elliot is the most comprehensive measurement in improving adolescent social skills. This evidenced by several articles that use this measurement and have a positive impact. The development of interventions on symbolic communication among adolescents with ASD needs to be applied in future research.
\end{abstract}

Keywords: Social intervention, autism, adolescence

Received II October 2019/Accepted 8 August 2019 @JEHCP All rights reserved

\section{Introduction}

Adolescence is a period of development that is between childhood and adulthood which involves several developmental processes such as social-emotional, biological, and cognitive development (Santrock, 20I4). Signs of adolescence can be found with the appearance of symptoms of puberty which are characteristic at this stage of development. Puberty in 
adolescence does not only involve changes in hormones and physical development, but changes also occur in their environmental processes, especially in building relationships with peers. Adolescents spend more time with peers who are almost the same age. Behind the beginning of the low supervision from more mature people, they place great hopes on peers around them (Brown \& Larson, 2009).

In the process of development, not all adolescents success in carrying out their development tasks, because there are some adolescents who experience disorders. Autism Spectrum Disorder (ASD) is one of them. The American Psychiatric Association (APA, 20I3) explained that ASD is a disorder that occurs with communication deficit characteristics, such as improper response to conversations, misreading of non-verbal interactions, and difficulty in building relationships with peers. While the American Psychological Association (APA) revealed that autism involves a disruption in social interactions and verbal and nonverbal communication, has limited interest, and tends to hurt themselves such as banging their heads and biting their hands.

ASD disorders certainly become a problem for adolescents who experience it. Because they have difficulties in establishing good relations with the surrounding environment, especially with peers. These disorders need special attention by the surrounding environment, parents, family, friends, and teachers to be among those who always pay attention to the disturbances that occur for adolescents with ASD. They can provide encouragement and motivation for their development in order to be able to go through the crisis they experience. ASD is a disorder caused by a lack of motivation from the surrounding environment. Therefore, encouragement becomes capital in helping adolescents who experience ASD (Chevallier et al., 20I2).

Individuals who experience ASD are included in individuals who have special needs and need to get special education and assistance from the surrounding environment (Permendikbud, 2014). Assistance that can be given to adolescents with ASD disorders can be by giving intervention. Some interventions such as intervention in cognitive, behavioral, and social intervention skills can be given to those who experience ASD (Van Schalkwyk \& Volkmar, 2015). Interventions must focus on improving communication, social, play and play skills 
(Lindgren \& Doobay, 20II). Therefore, a literature review of social interventions in adolescents with Autism Spectrum Disorder (ASD) was used in this study.

This literature review aims to analyze social interventions in adolescents who experience ASD. In analyzing this, the type of intervention and the impact of the intervention were also analyzed according to the selected study criteria. This is done to provide an overview of social interventions in enhancing the ability of adolescent relationships with ASD with the surrounding social environment, which can then become a guide and reference in implementing interventions in similar contexts in the future.

\section{Method}

Systematic Search Procedure

To identify this review process, literature searches were found using three online databases namely the Education Resources Information Center (ERIC) with the URL address eric.ed.gov, Springer Link with the URL address link.springer.com, and ScienceDirect with the URL address www.sciencedirect.com. To simplify the search process, the search is based on the "social intervention" and "autism spectrum disorder" keyword.

Some of the criteria specified in the search process consist of inclusion and exclusion categories. Inclusion criteria include I) Research that applies the process of social intervention, 2) Research using experimental methods, 3) Participants focus on adolescents who experience ASD, 4) Research from 2010 to 2018, 5) Articles downloaded in full, and 6) Literature used in English. While the exclusion criteria include articles involving children and adults, and articles that do not have procedures for implementing interventions, as well as articles that do not meet other inclusion criteria.

\section{Identification of Inclusion and Exclusion Criteria}

The article screening process begins with searching for articles that are in accordance with the keywords "social intervention" and "autism spectrum disorder" in the ERIC database, Springer Link, and ScienceDirect which found 420 articles. Then do the screening by looking 
at the suitability of the title with the review literature process. From this process were found 98, and 322 articles out. Then filtering was carried out in accordance with research using experimental design. In this process, 54 articles were found and 44 articles were out. The next step is screening the articles that apply the intervention process. Articles with the implementation of the intervention were found 34 and those who did not apply the intervention were 20 articles.

In the final stage, the screening process is narrowed with a focus on research from 2010 to 2018 and participants involving adolescents. Found 8 articles and 26 articles came out. 8 selected articles were then analyzed in-depth in the next process.

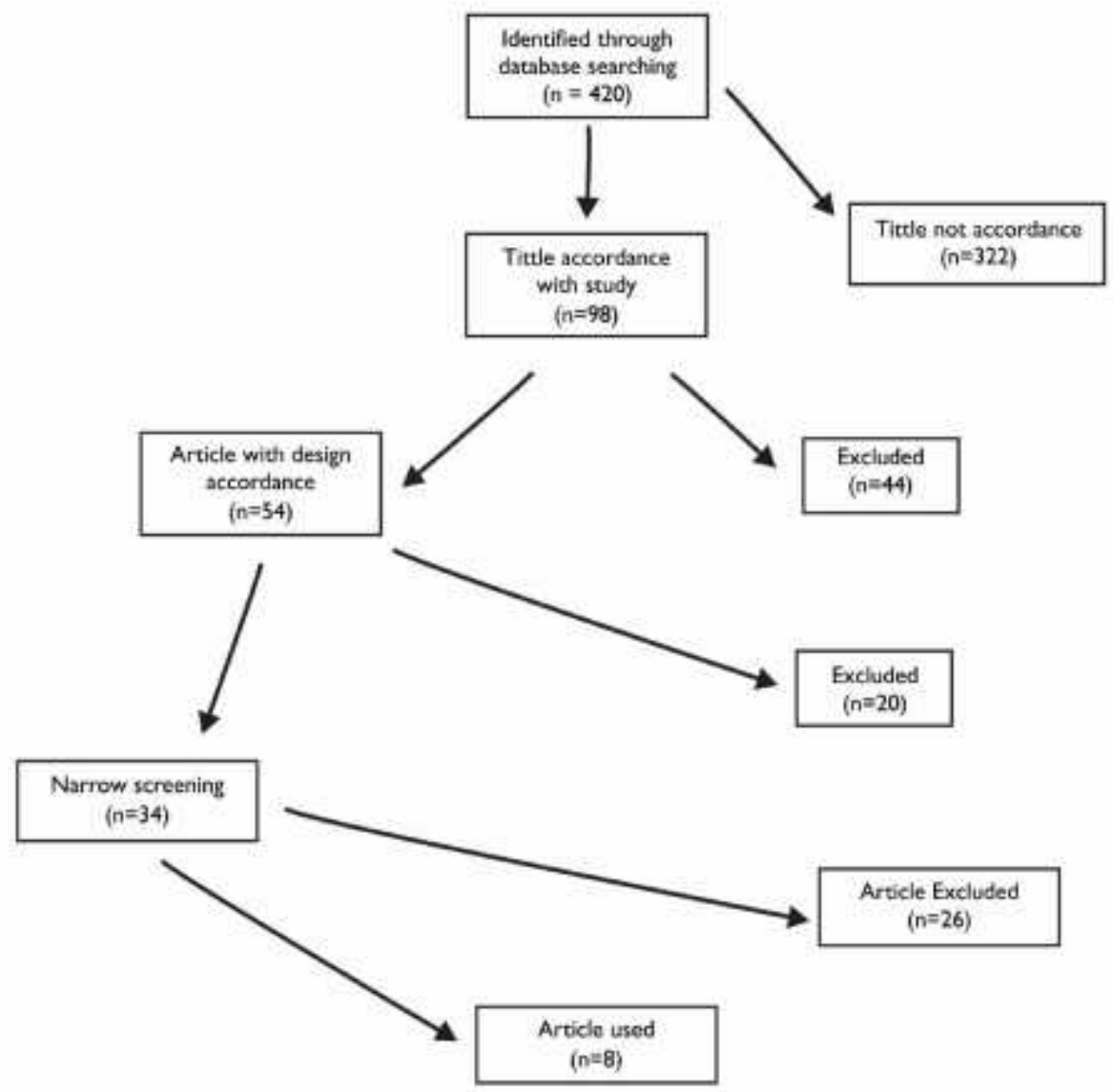




\section{Result and Discussion}

\section{Intervention Overview}

So far, we have found four types of social interventions that are believed to be able to have a positive impact on adolescents with autism spectrum disorder (ASD), namely The Program for Education and the Enrichment of Relational Skills (PEERS), Multimodal Anxiety and Social Skills Intervention (MASSI), Peer Network Intervention, and CBT-CSCA Interventions. By application, all four are able to have an impact on the development of adolescent skills with autism spectrum disorder (ASD).

The Program for Education and the Enrichment of Relational Skills (PEERS) is a parentassisted social skill group intervention with the aim of gaining knowledge about social knowledge in adolescents who experience Autism Spectrum Disorders (Laugeson et al., 2012; Gonring, Gerdes, \& Gardner, 2017). Group-based interventions in inclusion contexts differ from individual interventions because group-based interventions provide space for adolescents to practice social skills taught with peers (Wyman \& Claro, 2019).

Literature analysis found 5 articles from a total of 8 articles that applied PEERS interventions to adolescents who experienced ASD (Mandelberg et al., 20I4; Laugeson, et al., 20I4; Dolan et al, 2016; Laugeson et al., 20I2; Karst et al., 20I4).

Multimodal Anxiety and Social Skills Intervention (MASSI) is an intervention based on the principles of CBT in overcoming the thoughts, feelings, and behavior of individuals and the interaction between the three parts to produce the desired change (White et al., 2010; 20I3). The literature analysis found I study that applied MASSI intervention, namely in the literature of White et al (2013). In the implementation, MASSI is divided into 3 types, namely therapy for individuals, groups, and guidance from parents. In individuals, there are 13 sessions that last around 60-70 minutes, while in groups there are 7 sessions of 75 minutes each, and parental guidance is carried out for 15 minutes after each individual therapy session is completed.

Peer Network Intervention is one form of intervention that involves small groups of peers selected to provide support to individuals who experience problems in the social 
environment or those who experience ASD (Kamps et al., 2014) and provide opportunities for individuals to interact with peers (Sreckovic et al., 2017). These interventions are designed to improve relationships with peers and increase interaction between them by giving impetus to the social environment (Asmus et al., 2017; Carter et al., 2013; Biggs et al., 2018).

In general, the first step taken in this intervention is to observe for 10 minutes for adolescents who experience ASD with peers at lunch time. The intervention process occurs for 5 weeks at lunch time in an empty space.

CBT-CSCA interventions are based on cognitive-behavioral therapy, integrating mastery of behavior. The strategy used by this intervention by giving of training which includes didactic teaching, role-playing, modeling, behavioral training, coaching and homework given with supervision (Chan et al., 2018; Gresham et al., 200I). CBT-CSCA interventions conducted by Chan et al (2018) were first adopted and developed in the context of adolescents with Chinese citizenship.

CBT-CSCA is implemented in a community that facilitates adolescents who experience ASD in Hong Kong. This intervention was carried out in 4 groups, each consisting of 5-7 group members. Social competency training takes place with I5 sessions, each of which consists of 120 minutes using four main modules.

\section{Measurements}

In the 8 literature that has been analyzed, there are several measurements or scales used, such as the Social Skills Rating System (SSRS, Gresham \& Elliot, 2010; Mandelberg et al., 2014; Laugeson et al., 2014; Laugeson et al., 2012), Social Responsiveness Scale (CRS, Constantino, 2005; Mandelberg et al., 20l4, Laugeson et al., 2014; Laugeson et al., 2012; White et al., 20I3), The Quality of Play Questionnare (QPQ, Frankel \&Mintz, 20II; Mandelberg et al., 2014; Laugeson et al., 20I4; Laugeson et al., 2012), Test of Social Skills Knowledge Adolescents (TASSK, Laugeson\& Frankel, 2010; Mandelberg et al., 20l4; Laugeson et al., 2014; Dolan et al., 2016; Laugeson et al., 2012), Kaufman Brief Intelligence Test-Second Edition (KBIT-2, Kaufman \& Kaufman, 2005; Mandelberg et al., 20I4; Laugeson 
et al., 20I2), Vineland Adaptive Behavior Scales-Second Edition, Survey Form (Vineland-II, Sparrow, Balla, \& Cicchetti, 2005; Mandelberg et al., 20I4; Laugeson et al., 2012; White et al., 20I3).

There are also Friendships and Interventions Interview (FII) and Social Communication Questionnaires (SCQ; Rutter, Bailey, \& Lord, 2003; Mandelberg et al., 20I4), Social Anxiety Scale (SAS, La Greca \& Lopez, 1998; Laugeson et al., 2014), Friendship Qualities Scale (FQS, Bukowski et al., 1994; Laugeson et al., 2014), Piers-Harris Self-Concept Scale-Second Edition (PHS-2, Piers, 1984; Laugeson et al., 2014), The Contextual Assessment of Social Skills (CASS, Ratto et al., 2010; Dolan et al., 2016), Intervention for Adolescents with ASD: Programs for the Education and Enrichment of Relational Skills (PEERS, Laugeson et al, 2009; Dolan et al., 2016), Confusion, Hubbub, and Order Scale (CHAOS), Stress Index for Parents of Adolescents (SIPA), and Parenting Sense of Competence Scale (PSOC, Karst et al., 20I4).

Chan et al (2018) used the Multidimensional Social Competence Scale-Chinese Version (MSCS-C) and the Autism Spectrum Quotient-10 items-China version (AQ-10-C). Whereas White et al., 2013 used Autism Diagnostic Interview-Revised (ADI-R; Lord et al., 1994), Autism Diagnostic Observation Schedule (ADOS; Lord et al., 2002), Anxiety Disorders Interview Schedule for Children / Parents (ADIS- C / P; Silverman \& Albano, 1996), Wechsler Abbreviated Scale of Intelligence (WASI; Wechsler, 1999), Child and Adolescent Symptom Inventory-4 ASD Anxiety Scale (CASI-Anx; Sukhodolsky et al., 2008), Pediatric Anxiety Rating Scale (PARS; Research Units on Pediatric Psychopharmacology; Anxiety Study Group, RUPP 2002), Clinical Global Impressions-Improvement Scale (CGI-I; Guy, 1976), and Developmental Disabled Children Global Assessment Scale (DD-CGAS; Wagner et al., 2007). The complete resume of ASD measurement was showed in table I below. 
Table I

The Measurements Framework of Intervention

\begin{tabular}{ccccc}
\hline Study & Measurements Framework \\
\hline Whiteetal (20I3) & SSRS (Gresham \& Elliot, 20I0), CRS (Constantino, 2005), Vineland-II
\end{tabular}
(Sparrow, Balla, \& Cicchetti, 2005), ADI-R (Lordetal., 1994), ADOS (Lordetal, 2002), ADIS- C/P (Silverman \& Albano, 1996), WASI (Wechsler, 1999), CASIAnx (Sukhodolsky et al., 2008)

Mandelbergetal (2014) SSRS (Gresham \& Elliot, 2010), CRS (Constantino, 2005), QPQ (Frankel \& Mintz, 20II), TASSK (Laugeson \& Frankel, 20I0), KBIT-2 (Kaufman \& Kaufman, 2005), Vineland-II (Sparrow, Balla, \& Cicchetti, 2005), SCQ (Rutter, Bailey, \& Lord, 2003), Friendships and Interventions Interview (FII)

Laugesonetal (2014) SSRS (Gresham \& Elliot, 2010), CRS (Constantino, 2005), QPQ (Frankel \& Mintz, 20II), TASSK (Laugeson \& Frankel, 20I0),SAS (La Greca \& Lopez, 1998), PHS-2 (Piers, 1984)

Dolanetal (2016) TASSK (Laugeson \& Frankel, 2010),CASS (Rattoetal., 2010), PEERS (Laugeson et al., 2009)

Laugesonetal (2012) SSRS (Gresham \& Elliot, 20I0), CRS (Constantino, 2005), QPQ (Frankel \& Mintz, 20II), TASSK (Laugeson \& Frankel, 20I0), KBIT-2 (Kaufman \& Kaufman, 2005), Vineland-II (Sparrow, Balla, \& Cicchetti, 2005)

Karstetal (2014) CHAOS, SIPA, PSOC

Sreckovicetal (2017) Peer Network Strategies (Carter et al., 2013)

Chan etal(2018) MSCS-C, AQ-I0-C

The Impacts of Interventions

Some types of interventions applied in the 8literatures reviewed have the impact of the tests that have been applied. PEERS interventions were significantly able to improve social knowledge and abilities which included social communication, social motivation, social awareness, social cognition (Laugeson et al., 20I4; Laugeson et al., 20I2; Karst et al., 20I4). PERRS can also significantly increase adolescent vocal expression (Dolan et al., 2016) and decrease their autistic behavior (Laugeson et al., 20I4; Laugeson et al., 20I2). In general, PEERS are able to improve the quality of the overall relationship (Dolan et al., 2016; Laugeson et al., 2014; Laugeson et al., 2012) and can provide benefits in a period of I to 5 years. (Mandelberg et al., 20I4). 
While MASSI intervention is one intervention program that is very useful and can be recommended for subsequent implementation (White et al., 2013). Peer Network Intervention is also able to increase the social interaction of adolescents in secondary schools and is able to reduce the tendency of bullying behavior among them (Sreckovic, et al., 2017; Gardner et al., 2014). Peer Network Intervention is also able to improve the communication process of individuals and be able to develop their language skills (Kamps et al., 2014). In contrast to Biggs et al (2018) research which states that Peer Network Intervention is indeed able to improve the process of interaction with peers, but it does not improve their symbolic communication.

CBT-CSCA besides being able to improve social competence is also able to improve or reduce autistic symptoms, psychopathology, and stress experienced by parents (Chan et al., 2018). Some of the interventions that have been carried out also involve the role of parents in the process. Intervention programs and assistance in developing social competence of children assisted by parents are very helpful in the long term (Mandelberg et al., 2014) and can improve parents' self-efficacy in parenting (Karst et al., 2014). Table 2 below show the resultf of social intervention for ASD.

Table 2

Analysis Result for Social Intervention for Adolescents with Autism Spectrum Disorders (ASD) in several articles used

\begin{tabular}{|c|c|c|c|c|}
\hline Study & Design & Participants & Interventions & Effects \\
\hline $\begin{array}{l}\text { White } \\
\text { etal }(2013)\end{array}$ & Experiment & $\begin{array}{l}30 \text { Adolescents } \\
\text { with ASD and } \\
\text { Anxiety } \\
\text { symptoms of } \\
\text { moderator } \\
\text { greater severity }\end{array}$ & MASSI & $\begin{array}{l}\text { MASSI is a feasible treatment } \\
\text { program and further evaluation is } \\
\text { warranted }\end{array}$ \\
\hline $\begin{array}{l}\text { Mandelbergetal } \\
(20 \mid 4)\end{array}$ & Experiment & $\begin{array}{l}53 \text { Adolescent } \\
\text { participants } \\
\text { between } 12 \text { and } \\
18 \text { years and their } \\
\text { parents }\end{array}$ & PEERS & $\begin{array}{l}\text { The PEERS parent-assisted, } \\
\text { manualized method of social skills } \\
\text { training appears to lead to long- } \\
\text { term sustained benefits I--5 years } \\
\text { following treatment. }\end{array}$ \\
\hline $\begin{array}{l}\text { Laugeson } \\
\text { etal (2014) }\end{array}$ & Experiment & $\begin{array}{l}73 \text { Middle school } \\
\text { students } \\
\text { (adolescence) } \\
\text { with ASD along } \\
\text { with their parents } \\
\text { and teachers }\end{array}$ & $\begin{array}{l}\text { The UCLA } \\
\text { PEERS } \\
\text { Program }\end{array}$ & $\begin{array}{l}\text { Results reveal that in comparison } \\
\text { to an active treatment control } \\
\text { group, participants in the PEERS } \\
\text { treatment group significantly } \\
\text { improved in social functioning in } \\
\text { the areas of teacher-reported } \\
\text { social responsiveness, social } \\
\text { communication, social motivation, }\end{array}$ \\
\hline
\end{tabular}




\begin{tabular}{|c|c|c|c|c|}
\hline $\begin{array}{l}\text { Dolan etal } \\
(2016)\end{array}$ & Experiment & $\begin{array}{l}58 \text { Participants } \\
\text { with ASD in age } \\
\text { from II tol } 6 \\
\text { years old } \\
\text { adolescents with } \\
\text { ASD }\end{array}$ & PEERS & $\begin{array}{l}\text { PEERS demonstrated significantly } \\
\text { improved vocal expressiveness, as } \\
\text { well as a trend toward improved } \\
\text { overall quality of rapport }\end{array}$ \\
\hline $\begin{array}{l}\text { Laugeson } \\
\text { etal }(2012)\end{array}$ & Experiment & $\begin{array}{l}28 \text { Middle school } \\
\text { and high schools } \\
\text { adolescents } \\
\text { with ASD ranging } \\
\text { from } 12 \text { to } 17 \\
\text { years of age }\end{array}$ & PEERS & $\begin{array}{l}\text { The teens who receiving PEERS } \\
\text { significantly improved their social } \\
\text { skills knowledge, social } \\
\text { responsiveness, and overall social } \\
\text { skills in the areas of social } \\
\text { communication, social cognition, } \\
\text { social awareness, social motivation, } \\
\text { assertion, cooperation, and } \\
\text { responsibility, while decreasing } \\
\text { autistic mannerisms and increasing } \\
\text { the frequency of peer interactions }\end{array}$ \\
\hline $\begin{array}{l}\text { Karst etal } \\
(20 \mid 4)\end{array}$ & Experiment & $\begin{array}{l}64 \text { participants } \\
\text { (32 caregiversand } \\
32 \text { adolescents) }\end{array}$ & PEERS & $\begin{array}{l}\text { The beneficial effects for the } \\
\text { experimental group in the domain } \\
\text { of family chaos compared to the } \\
\text { waitlist control, while parents in } \\
\text { the PEERS experimental group also } \\
\text { demonstrated increased parenting } \\
\text { self-efficacy }\end{array}$ \\
\hline $\begin{array}{l}\text { Sreckovic } \\
\text { etal (20I7) }\end{array}$ & Experiment & $\begin{array}{l}\text { Adolescentson } 15 \\
\text { years }\end{array}$ & $\begin{array}{l}\text { Peer } \\
\text { Network } \\
\text { Interventions }\end{array}$ & $\begin{array}{l}\text { The peer networks are efective at } \\
\text { increasing social interactions of } \\
\text { secondary students with ASD and } \\
\text { provide preliminary support for } \\
\text { the use of peer networks to } \\
\text { reduce rates of bullying } \\
\text { victimization }\end{array}$ \\
\hline $\begin{array}{l}\text { Chan etal } \\
(2018)\end{array}$ & Experiment & $\begin{array}{l}\text { Adolesncetsbetw } \\
\text { een } 12 \text { and } 17 \\
\text { yearsofage }\end{array}$ & CBT-CSCA & $\begin{array}{l}\text { Signifcant improvements in social } \\
\text { competence,autistic symptoms and } \\
\text { general psychopathology at post- } \\
\text { training and 3-month follow-up } \\
\text { were reported by the parents }\end{array}$ \\
\hline
\end{tabular}

\section{Conclusion}

The social skills of adolescents with autism spectrum disorder (ASD) can be improved and developed through several interventions such as the Program for the Education and Enrichment of Relational Skills (PEERS), Multimodal Anxiety and Social Skills Intervention (MASSI), Peer Network Intervention, and CBT-CSCA. PEERS interventions are still widely used in dealing with ASD disorders in adolescents, while measurement with the Social Skills 
Rating System (SSRS, Gresham \& Elliot, 2010) is the most comprehensive measurement in improving adolescent social skills. The impact of some of these interventions is very significant in increasing the knowledge and skills related to the surrounding social environment in adolescents.

\section{Limitation}

The literature review is currently only done on 3 online databases with keywords search "social intervention" and "autism spectrum disorders".

\section{Further Research}

Although intervention with Peer Network Intervention is one of the interventions in adolescents who experience ASD, it needs to be tested again with a focus on increasing adolescent symbolic communication. Because the intervention has not been able to significantly improve adolescent symbolic communication with peers (Biggs et al., 2018). Some of the reviewed literature has implemented interventions in the context of each region in general, such as Asia, Latin, Caucasian, African, American. It is recommended that further research be applied to specific areas in a narrow context and interventions and measurements are also adjusted to that specific area, as Chan et al (2018) have done.

\section{References}

American Psychiatric Association. (20I3). Diagnostic and statistical manual of mental disorder edition "DSM-5". Washington DC: American Psychiatric Publishing.

American Psychological Association. (2019). Autism. Accessed on 4 April 2019 from https://www.apa.org/topics/autism.

Asmus, J. M., Carter, E. W., Moss, C. K., Biggs, E. E., Bolt, D. M., Born, T. L., BottemaBeutel, K., Brock, M. E., Cattey, G. N., Cooney, M., Fesperman, E. S., Hochman, J. M., Huber, H. B., Lequia, J. L., Lyons, G. L., Vincent, L. B., \& Weir, K. (2017). Efficacy and social validity of peer network interventions for high school students with severe disabilities. American Journal on Intellectual and Developmental Disabilities, 122, I I8-137. Doi: I0.1352/1944-7558-122.2.1 I8. 
Biggs, E. E., Carter, E. W., Bumble, J. L., Barness, K., \& Mazur, E. L. (20l8). Enhancing peer network interventions for students with complex communication needs. Exceptional Children, I-20. Doi 10.1 I77/0014402918792899.

Brown, B. B., \& Larson, J. (2009). Peer relationships in adolescence. Handbook of Adolescent Psychology. Doi 10.1002/9780470479193.adlpsy002004.

Bukowski, W. M., Hoza, B., \& Boivin, M. (1994). Measuring friendship quality during pre- and early adolescence: The development and psychometric properties of the friendship qualities scale.Journal of Social and Personal Relationships, I I (3), 47I-484.

Carter, E. W., Asmus, J., Moss, C. K., Cooney, M., Weir, K., Vincent, L., Born, T., Hochman, J. M., Bottema-Beutel, K., \&Fesperman, E. (20I3). Peer network strategies to foster social connections among adolescents with and without severe disabilities. TEACHING Exceptional Children, 46, 5I-59. Doil 0.I I77/00400599/304600206.

Chan, R. W. S., Leung, C. N. W., Yiu Ng, D. C., \&Yau, S. S. W. (2018). Validating a culturally-sensitive social competence training programme for adolescents with asd in a chinese context: An initial investigation. J Autism Dev Disord, 48, 450-460. Doi 10.1007/s 10803-017-3335-6.

Chevallier, C., Kohls, G., Troiani, V., Brodkin, E. S., \& Schultz, R. T. (2012). The social motivation theory of autism. Trends Cogn Si, I6(4). 23I-239. Doi 10.1016/j.tics.2012.02.007.

Constantino, J. N. (2005). Social responsiveness scale. Los Angeles: Western Psychological Services.

Dolan, B. K., van Hecke, A. V., Carson, A. M., Karst, J. S., Stevens, S., Schohl, K. A., Potts, S., Kahne, J., Linneman, N., Remmel, R., \& Hummel, E. (2016). Brief report: Assessment of intervention effects on in vivo peer interactions in adolescents with autism spectrum disorders (ASD). J Autism Dev Disord. Doi 10.1007/s 10803-0 16-2738-0.

Frankel, F., \&Mintz, J. (20II). maternal reports of play dates of clinic referred and community children. Journal of Child and Family Studies, 20(5), 623-630.

Gardner, K. F., Carter, E. W., Gustafson, J. R., Hochman, J. M., Harvey, M. N., Mullins, T. S., \& Fan, H. (20l4). Effects of peer networks on the social interactions of high school students with autism spectrum disorders. Research and Practice for Persons with Severe Disabilities, 39(2), I00-I I8. Doi I0.II77/I5407969|4544550.

Gonring, K., Gerdes, A., \& Gardner, D. (2017). Program for the education and enrichment of relational skills: Parental outcomes with an ADHD sample. Child \& Family Behavior Therapy, 39(I), 19-42. Doi 10.1080/073 I7I 07.20I6.1268003 
Gresham, F. M., \& Elliott, S. (1990). The social skills rating system. Circle Pines, MN: American Guidance Service.

Gresham, F., Sugai, G., \& Horner, R. (200I). Interpreting outcomes of social skills training for students with high incidence disabilities. Exceptional Children, 67(3), 33I-345.

Guy, W. (1976). ECDEU assessment manual for psychopharmacology. us dept health, education, and welfare publication; ADM no. 76-338. Rockville, MD: National Institute of Mental Health.

Kamps, D., Thiemann-Bourque, K., Heitzman-Powell, L., Schwartz, I., Rosenberg, N., Mason, R., \& Cox, S. (2014). A comprehensive peer network intervention to improve social communication of children with autism spectrum disorders: A randomized trial in kindergarten and first grade. J Autism Dev Disord. Doi 10.1007/s 10803-0 I4-2340-2.

Karst. J. S., van Hecke, A. V., Carson, A. M., Stevens, S., Schohl, K., \& Dolan, B. (20I4). Parent and family outcomes of PEERS: A social skills intervention for adolescents with autism spectrum disorder. J Autism Dev Disord, 45, 752-765. Doi |0.1007/s |0803-0|4-223|-6.

Kaufman, A. S., \& Kaufman, N. L. (2005). Kaufman brief intelligence test-second edition. Circle Pines, MN: American Guidance Service.

La Greca, A. M., \& Lopez, N. (1998). Social anxiety among adolescents: Linkages with peer relations and friendships. Journal of Abnormal Child Psychology, 26, 83-94.

Laugeson, E. A., \& Frankel, F. (2010). Social skills for teenagers with developmental and autism spectrum disorder: The PEERS treatment manual. New York: Routledge.

Laugeson, E. A., Frankel, F., Mogil, C., \& Dillon, A. R. (2009). Parent-assisted social skills training to improve friendships in teens with autism spectrum disorders. Journal of Autism and Developmental Disorders, 39(4), 596-606.

Laugeson. E. A., Frankel, F., Gantman, A., Dillon, A. R., \& Mogil, C. (2012). Evidence-based social skills training for adolescents with autism spectrum disorders: The UCLA PEERS program. J Autism Dev Disord, 42, I025-I036. Doi 10.1007/s I0803-0I I-I339-I.

Laugeson. E. A., Ellingsen, R., Sanderson, J., Tucci, L., \& Bates, S. (20I4). The ABC's of teaching social skills to adolescents with autism spectrum disorders in the classroom: The UCLA PEERS program. J Autism Dev Disord. Doi 10.1007/s I0803-0 I4-2 I08-8.

Lindgren, S., \& Doobay, L. (20I I). Evidence-based interventions for autism spectrum disorders. Center for Disabilities and Development of the University of Lowa: United States of America. 
Lord, C., Rutter, M., \& Le Couteur, A. (1994). Autism diagnostic interview-revised: A revised version of a diagnostic interview for caregivers of individuals with possible pervasive developmental disorders.Journal of Autism and Developmental Disorders, 24 (5), 659-685. Doi: I0.1007/BF02 I72I45.

Lord, C., Rutter, M., DiLavore, P. C., \& Risi, S. (2002). Autism diagnostic observation schedule. Los Angeles: Western Psychological Services.

Mandelberg. J., Laugeson, E. A., Cunningham, T. D., Ellingsen, R., Bates, S., \& Frankel, F. (20I4). Long-term treatment outcomes for parent-assisted social skills training for adolescents with autism spectrum disorders: The UCLA PEERS program. Journal of Mental Health Research in Intellectual Disabilities, 7, 45-73. Doi 10.1080/19315864.2012.730600.

Permendikbud. (20I4). Law Number 157 of 2014 concerning the Special Education Curriculum. Article I, 2 and 3 (In Indonesian).

Piers, E. V. (1984). Piers-harris children's self-concept scale-revised manual. Los Angeles: Western Psychological Services.

Ratto, A. B., Turner-Brown, L., Rupp, B. M., Mesibov, G. B., \& Penn, D. L. (2010). Development of the contextual assessment of social skills (CASS): A role play measure of social skill for individuals with high-functioning autism. Journal of Autism and Developmental Disorders, 4I(9), I277-1286.

Research Units on Pediatric Psychopharmacology Anxiety Study Group. (2002). The pediatric anxiety rating scale (PARS): Development and psychometric properties. Journal of the American Academy of Child \& Adolescent Psychiatry, 4I, I06 I-I069.

Rutter, M., Bailey, A., \& Lord, K. (2003). The social communication questionnaire. Los Angeles, CA: Western Psychological Services.

Santrock, J. W. (20|4). Adolescence (fifteenth edition). New York: McGraw-Hill Education.

Silverman, W. K., \& Albano, A. M. (1996). Anxiety disorders interview schedule for DSM-IV. San Antonio, TX: The Psychological Corporation.

Sparrow, S., Balla, D., \& Cicchetti, D. V. (2005). The vineland adaptive behavior scales-second edition. Circle Pines, MN: American Guidance Service.

Sreckovic, M. A., Hume, K., \& Able, H. (2017). Examining the efficacy of peer network interventions on the social interactions of high school students with autism spectrum disorder. J Autism Dev Disord, 47, 2556-2574. Doi 10.1007/s 10803-0I7-3 I7I-8.

Sukhodolsky, D. G., Scahill, L., Gadow, K. D., Arnold, L. E., Aman, M. G., McDougle, C. J., McCracken, J. T., Tierney, E., White, S. W., Lecavalier, L., \& Vitiello, B. (2008). 
Parent-rated anxiety symptoms in children with pervasive developmental disorders: Frequency and association with core autism symptoms and cognitive functioning. Journal of Abnormal Child Psychology, 36, II7-128.

Van Schalkwyk, G. I. \& Volkmar, F. R. (20I5). Autism spectrum disorders. The Psychoanalytic Study of the Child, 69(I), 219-24I. Doil 0.1080/00797308.2016.II 785529.

Wagner, A., Lecavalier, L., Arnold, L. E., Aman, M. G., Scahill, L., Stigler, K. A., Johnson, C. R., McDougle, C. J., \& Vitiello, B. (2007). Developmental disabilities modification of children's global assessment scale (DD-CGAS). Biological Psychiatry, 6I, 504-5II. Doi I0.1016/j.biopsych. 2007.01.00I.

Wechsler, D. (1999). Wechsler abbreviated scale of intelligence (WASI). San Antonio, TX: Harcourt Assessment.

White, S. W., Ollendick, T., Albano, A. M., Oswald, D., Johnson, C., Southam-Gerow, M. A., Kim, I., \&Scahill, L. (20I2). Randomized controlled trial: Multimodal anxiety and social skill intervention for adolescents with autism spectrum disorder. J Autism Dev Disord, 43, 382-394. Doi 10.1007/s 10803-012-1577-x.

Wyman, J., \& Claro, A. (2019). The UCLA PEERS school-based program: Treatment outcomes for improving social functioning in adolescents and young adults with autism spectrum disorder and those with cognitive deficits. Journal of Autism and Developmental Disorders. Doi 10.1007/s 10803-019-03943-z. 